\title{
Influence of Silane Content on the Optical Properties of Sol Gel Derived Spin Coated Silica Thin Films
}

\author{
R.K. Satvekar, M.R. Phadatare, V.A. Karande, R.N. Patil, B.M. Tiwale and \\ S.H. Pawar * \\ Centre for Interdisciplinary Research, D. Y. Patil University, Kolhapur-416006, \\ India. \\ *Corresponding e-mail: pawar_s_h@yahoo.com
}

\begin{abstract}
Sol gel technique in combination with spin coating method was utilized for the synthesis of silica thin films. Tetraethyl orthosilicate (TEOS) alkoxide silane precursor was used for one step synthesis of silica sol with $0.1 \mathrm{M}$ HCL as a catalyst. Casting solution of silica sol was spin coated on glass substrate. The X-ray diffraction pattern revealed that the sample possesses amorphous silica matrix. Thin films were characterized by Fourier transform infrared spectroscopy (FTIR) and UV-Visible spectroscopy techniques to compare the effect of TEOS concentration. The optical properties of the silica thin films revealed that thin films have 90-95\% transmittance in the visible range.
\end{abstract}

Keywords: Sol gel technique, Spin coating, thin film, Silica matrix, Tetraethylorthosilicate (TEOS).

\section{Introduction}

The sol-gel technique is earning the worldwide attention of researchers in the field of material science, due to its versatility in synthesizing inorganic nanomaterials at mild conditions [1]. High purity, homogeneity, controlled porosity, stable temperature, nanoscale structuring, physical rigidity, high photochemical and thermal stability, excellent optical transparency are the most remarkable features offered by this method for generating highly sensitive and selective matrices to incorporate in various biomedical applications. 
The inorganic nanomaterials produced by sol gel method are particularly attractive for fabrication of biosensors since they possesses wide range of physical attributes such as $\mathrm{pH}$, temperature, viscosity, water and solvent content. These properties are tailored by different experimental conditions. Sol gel technique yields a matrix that retains native conformation and reactivity of biomolecules.

In present investigation, sol gel technique is used to synthesize silica matrix as it is chemically inert, exhibits negligible swelling in aqueous solution, does not tend to be subject to microbial attack, optically transparent and, most importantly, it can enhance the stability of the encapsulated biomolecules by protecting it from variations in temperature or $\mathrm{pH}[2]$.

Enzyme nanobiosensor plays a vital role in diagnosis of various diseases. The success of any enzyme sensor depends on how well it retains its enzymatic activity on transducer. The most important part of a biosensor is the immobilization of a desired enzyme. However, the usefulness of immobilized enzyme on electrodes depends on factors such as the immobilization method, the chemical and physical conditions (such as $\mathrm{pH}$, temperature and contaminants), thickness and stability of the membrane used to couple the enzyme. Immobilization of enzyme in several matrices has been used for the fabrication of biosensors for estimation of glucose [3], lactate [4], cholesterol [5] etc.

Various physical and chemical deposition techniques have been utilized to prepare thin films including chemical bath deposition, dip coating, Spray Pyrolysis Method and spin coating. However, spin coating technique is widely employed for the highly reproducible fabrication of thin film over large areas with high structural uniformity and homogeneity at ambient temperature. For synthesis of silica materials, the change in porosity can also be important for maximum loading of enzyme and less likely to leach the encapsulated biomolecules. The porosity of sol gel thin films allows small reactant molecules to diffuse into the matrix while the large enzyme macromolecules get trapped in the pores. The reaction in the pores is studied by using the transparency of thin films which can be used in optical biosensor [6]. Thus, the study of the synthesis conditions and the related resulting properties of the xerogel are very important to understand the hybrid sol gel systems for application in biosensor.

In present manuscript, an effect of various concentrations of TEOS on the optical properties of silica thin films has been studied. The silica thin films has been characterized by X-ray diffraction (XRD), Fourier transform infrared spectroscopy (FTIR) and UV visible spectroscopy techniques.

\section{Materials and Methods}

\subsection{Materials}

Tetraethylorthosilicate (TEOS) was procured from Sigma Aldrich and used without further purification. Methanol, propan-2-ol, hydrochloric acid and nitric 
acid were of analytical grade. Microscopic slides (scientific plaza) were used as glass substrate.

\subsection{Instrumentation}

$\mathrm{X}$-ray diffraction measurement was carried out with INXITU X-ray diffractometer equipped with a crystal monochromator employing $\mathrm{Cu}-\mathrm{K}_{\alpha}$ radiation of wavelength $1.5406 \AA$ in $2 \theta$ range from 10 to $55^{\circ}$. The optical activity of Tetraethylorthosilicate sol-gel thin films was monitored by using a UV-visible spectrophotometer (Shimazdu model 1800). The Fourier-transform infrared spectra of Tetraethylorthosilicate sol-gel thin films were recorded using a Nicolet FTIR spectrometer (Model 510 P).

\section{Experimental procedures}

\subsection{Preparation of silica stock solution}

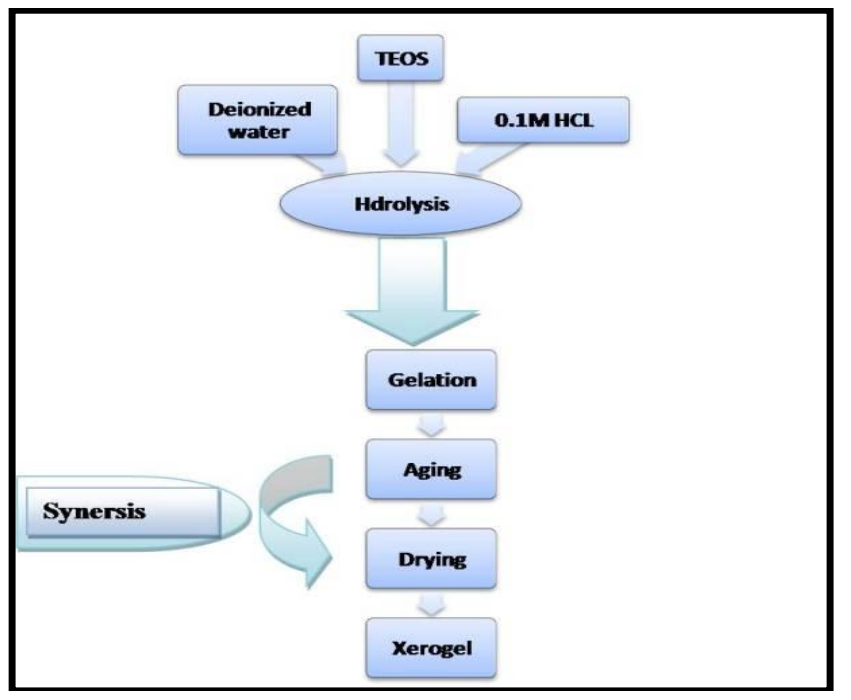

Fig 1: The schematic representation of sol gel technique

The preparation of silica samples were carried out by previously reported method [7]. The sols were prepared by hydrolysis and condensation of TEOS (tetra ethyl orthosilicate) in presence of water and hydrochloric acid $(0.1 \mathrm{M})$ with different TEOS concentrations. The samples were prepared for the various concentrations and thin films were prepared. Out of these, thin films prepared from samples $A_{1}$ and $A_{2}$ are crack free and uniform in nature. Hence, these are chosen for further study and explained in detail. The sample $A_{1}$ was prepared by mixing $4.5 \mathrm{ml}$ of TEOS and $0.25 \mathrm{ml}$ of $0.1 \mathrm{M}$ HCL in $1.4 \mathrm{ml}$ of double distilled water. Sample $\mathrm{A}_{2}$ was prepared by adding $2 \mathrm{ml}$ of TEOS and $0.25 \mathrm{ml}$ of $0.1 \mathrm{M} \mathrm{HCL}$ in $1.5 \mathrm{ml}$ of 
double distilled water. These reaction mixtures were placed in $25 \mathrm{ml}$ stopper glass container and stirred for $5 \mathrm{hrs}$ at $300 \mathrm{rpm}$ until visible homogeneity was obtained. The samples $A_{1}$ and $A_{2}$ were further kept in polystyrene container for aging about $24 \mathrm{hrs}$ and used as stock solutions for the preparation of thin films.

\subsection{Preparation of thin film}

\subsubsection{Pre-treatment for glass plates}

Prior to casting, glass plates were sonicated in distilled water for 30 minutes to remove impurities. These glass plates were etched by treating with concentrated $\mathrm{HNO}_{3}$ for $2 \mathrm{~h}$ Further, these plates were washed many times with double distilled water. These pre-treated glass plates wetted with propan-2-ol for even spreading of stock solution.

\subsubsection{Spin coating}

The clear stock solutions of samples $A_{1}$ and $A_{2}$ further diluted in methanol (1:3). Methanol was used to decrease the viscosity and to enhance spreading of silica sol on substrate. About $100 \mu \mathrm{l}$ of diluted stock solution was placed on glass plate (area about $4 \mathrm{~cm}^{2}$ ) and spun at $2800 \mathrm{rpm}$ for $15 \mathrm{~min}$ by using spin coater. These films were then dried at room temperature.

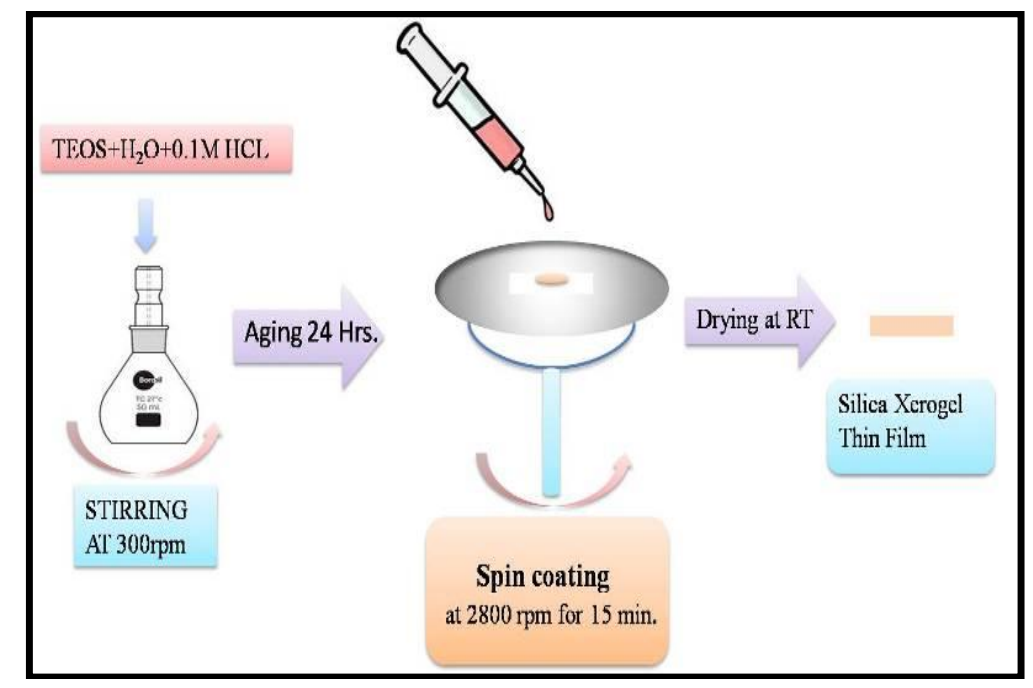

Fig 2: Preparation of silica thin films by spin coating method

The main reactions of the sol-gel process are the hydrolysis and polycondensation of silicon alkoxide that result in a cross linked silica network. Considering that the water is a byproduct of the polycondensation reaction, the $\mathrm{H} 2 \mathrm{O} / \mathrm{TEOS}$ molar ratio of 2 is theoretically sufficient to promote a complete hydrolysis and condensation to yield anhydrous silica as illustrated by following equation 


$$
\mathrm{Si}(\mathrm{OR})_{4}+4 \mathrm{H}_{2} \mathrm{O} \stackrel{\text { dil. } \mathrm{HCL}}{\longrightarrow} \mathrm{Si}(\mathrm{OH})_{4}+4 \mathrm{ROH}
$$

Where R stands for methyl or ethyl group.

However, it was reported that variations in $\mathrm{H}_{2} \mathrm{O}$ /TEOS molar ratios during the synthesis of pure inorganic silica, results in change in the porosity and pore size distribution of the obtained xerogel $[8,9]$. It was investigated that as the TEOS concentration decreases, the gelation time increases as shown in Table 1.

Table 1 Effect of silane content on viscosity and gelation time of the gel

\begin{tabular}{|c|c|c|c|c|c|}
\hline Samples & $\begin{array}{c}\text { TEOS:H } \\
\text { Molar ratio }\end{array}$ & $\begin{array}{c}\text { Stirring } \\
\text { Hrs. }\end{array}$ & $\begin{array}{c}\text { Ageing } \\
\text { Hrs. }\end{array}$ & $\begin{array}{c}\text { Viscosity } \\
\mathrm{cP}\end{array}$ & $\begin{array}{c}\text { Gelation Time } \\
\mathrm{t}_{\text {gel }} \text { (day) }\end{array}$ \\
\hline $\mathbf{A}_{\mathbf{1}}$ & $18: 5.6: 1$ & 5 & 24 & 14 & 5 \\
\hline $\mathbf{A}_{\mathbf{2}}$ & $8: 5.6: 1$ & 5 & 24 & 16 & 3 \\
\hline
\end{tabular}

\section{Results and Discussion}

\subsection{X- Ray Diffraction}

The phase formation process in silica matrix triggered by sol gel technique was monitored using XRD (as shown in Fig 3). For the as-dried gel, a much broadened peak over the $2 \theta$ range of $20-27^{\circ}$ is observed, corresponding to the amorphous silica matrix [10]. This indicates that no crystalline phase was formed during the initial drying of thin films prepared with TEOS at room temperature.

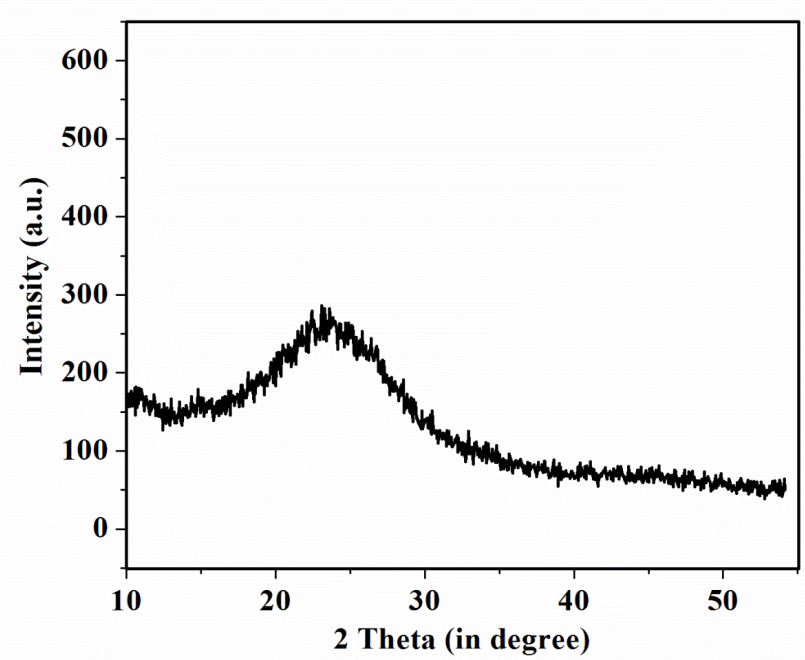

Fig 3: The X-ray diffraction pattern of TEOS based silica thin films 


\subsection{FTIR}

The FTIR spectra of samples of two different concentrations of TEOS are given in Fig4. The silica gel spectra illustrate several frequency regions as given below.

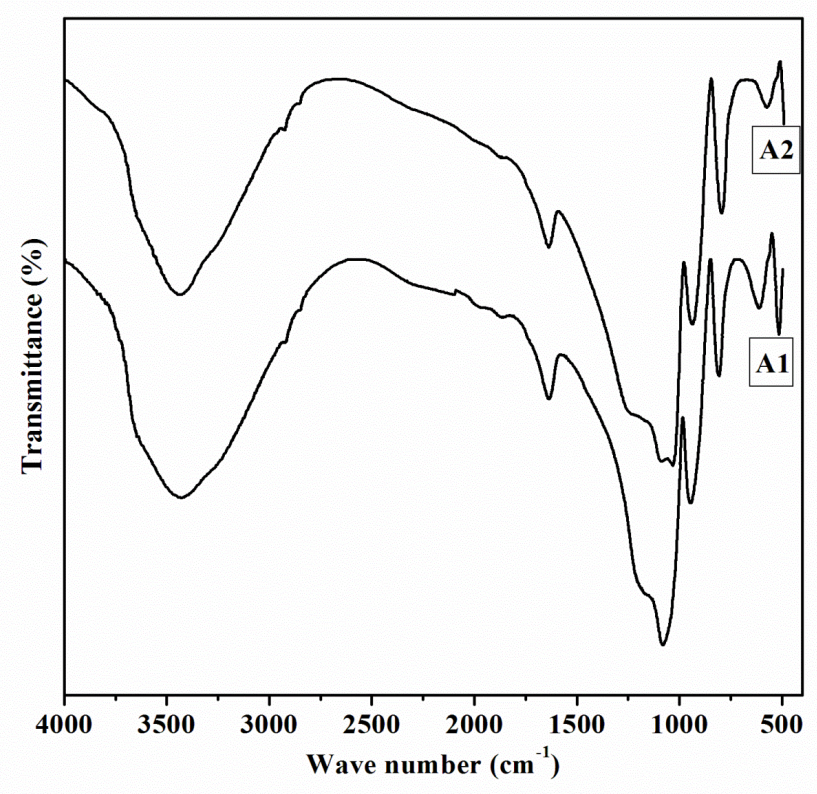

Fig 4: FTIR spectra for sample $\mathrm{A}_{1}$ and sample $\mathrm{A}_{2}$

a) $4000 \mathrm{~cm}^{-1}-3000 \mathrm{~cm}^{-1}$ : In this spectral range, the bands are mainly due to overtones and combination of vibration of $\mathrm{Si}-\mathrm{OH}$ or $\mathrm{H}_{2} \mathrm{O}$. The band at 3430-3445 $\mathrm{cm}^{-1}$ corresponds to molecular water hydrogen bonded to $\mathrm{Si}-\mathrm{OH}$ group [11].

b) $3000 \mathrm{~cm}^{-1}-1350 \mathrm{~cm}^{-1}$ : In this spectral range, the bands are due to the overtones and combination of vibration of organic residue, molecular water and $\mathrm{SiO}_{2}$ network. The band at $1638 \mathrm{~cm}^{-1}$ corresponds to vibration of molecular water. In spectra, water bands observed at around $1640 \mathrm{~cm}^{-1}$ corresponding to bending vibrations indicate hygroscopic character of the powdered samples [12]

c) $1300 \mathrm{~cm}^{-1}-400 \mathrm{~cm}^{-1}$ : This spectral region is associated with combinations of vibration of silica network. The band at $1082 \mathrm{~cm}^{-1}$ assign to asymmetric stretching vibrations of Si-O-Si bridging sequences. The band at $937-944 \mathrm{~cm}^{-1}$ attributed to stretching vibrations of free silanol group on surface of silica network. The band at 791-795 $\mathrm{cm}^{-1}$ corresponds to bending vibration of $\mathrm{C}-\mathrm{H}$ of $\mathrm{CH}_{3}-\mathrm{Si}$ group. The band at 470- $474 \mathrm{~cm}^{-1}$ associated with Si-O-Si bond bending vibration.

It is clear that the effect of water content in sol is pronounced for gel. The samples $A_{1}$ and $A_{2}$ show slight differences in intensity of peaks. The broad peak in 1400$1600 \mathrm{~cm}^{-1}$ region confirms the presence of $\mathrm{SiO}_{4}$. The intensity of absorption decreases on low frequency side of $1082-1032 \mathrm{~cm}^{-1}$ and $944-937 \mathrm{~cm}^{-1}$ bands and 
increases at high frequency peak $3430-3445 \mathrm{~cm}^{-1}, 1635-1638 \mathrm{~cm}^{-1}, 791-795 \mathrm{~cm}^{-1}$, $470-474 \mathrm{~cm}^{-1}$.

\subsection{UV-Visible spectrophotometry}

The optical properties of silica thin films were studied by recording the spectra over 400 and $1100 \mathrm{~nm}$ using a UV-VIS (Shimazdu model 1800) spectrophotometer (as shown in Fig 5). The optical properties revealed the formation of highly transparent silica thin films. The optical properties of silica thin films changes with decrease in silane content. Both films show the similar behavior up to the wavelength $600 \mathrm{~nm}$, after that films show a variation in transmittance. The thin film prepared by using sample $\mathrm{A}_{2}$ shows slight increase in the transmittance about $95 \%$ in range of wavelength $600 \mathrm{~nm}$ to $1100 \mathrm{~nm}$ as compared to the thin film prepared by using sample $A_{1}(88 \%)$. This behavior may be due to the less silane content in sample $A_{2}$ as compared to sample $A_{1}$. However, this increase in transmittance of thin film of sample $A_{2}$ is favorable for fabrication of biosensor due to its greater optical transparency.

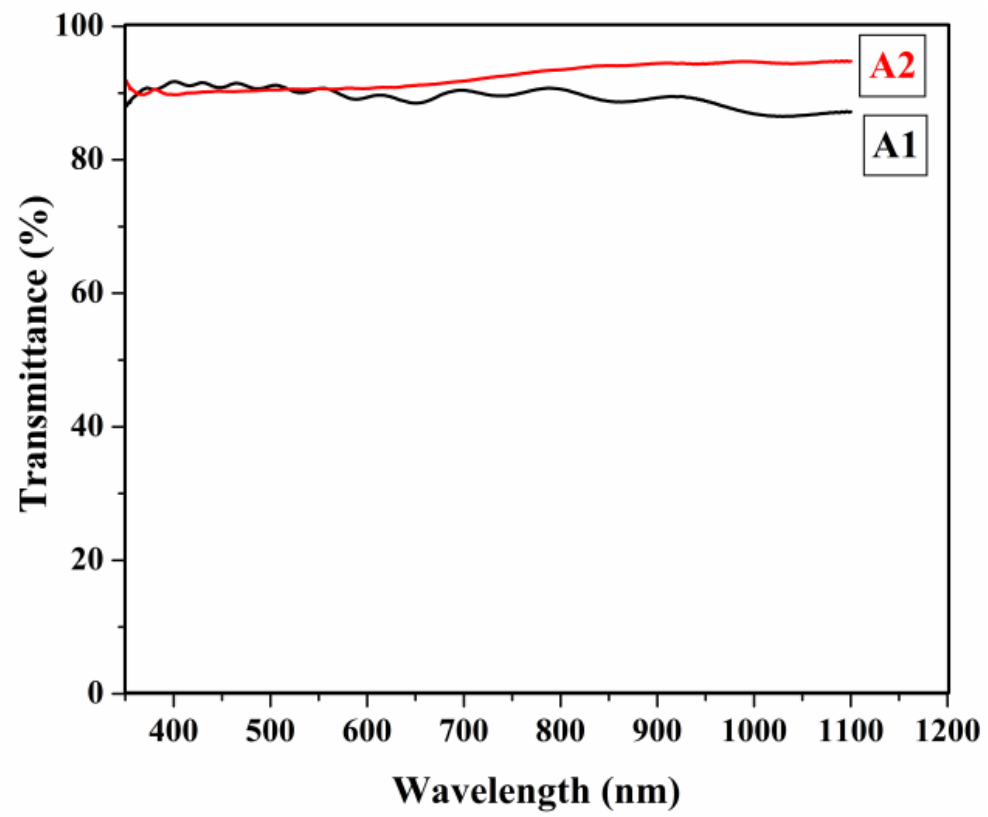

Fig 5: Transmittance spectra of silica thin films of samples $A_{1}$ and $A_{2}$

\section{Conclusions}

This article has addressed influence of silane content on optical properties of thin films. The silica thin films were synthesized using sol gel technique. The spin coating method was employed for synthesis of uniform and crack free thin films. The results showed that the optical properties of silica thin films were affected by 
decrease in silane (TEOS) concentration. The greater optical transparency of the silica thin film prepared by using the sample $A_{2}$ makes it valuable in the application of biosensor.

\section{Acknowledgement}

Authors are very much grateful to D. Y. Patil University, Kolhapur for financial support received under the sponsored project DYPU/BMT/R\&D/100.

\section{References}

[1] C.J. Brinker, G.W. Scherer, Sol Gel Science: the Physics and Chemistry of Sol Gel Processing. Academic Press, San Diego (1990).

[2] D. Avnir, T. Coradin, O. Levc, J. Livageb, Recent bio-applications of sol-gel materials, J Mater Chem 16 (2006) 1013-1030.

[3] Y. Zoua, C. Xiang, L.X. Suna, F. Xua, Glucose biosensor based on electrodeposition of platinum nanoparticles onto carbon nanotubes and immobilizing enzyme with chitosan- $\mathrm{SiO}_{2}$ sol-gel, Biosensors and Bioelectronics 23 (2008) 1010-1016.

[4] A. Chaubey, M. Gerard, V.S. Singh, B.D. Malhotra, Immobilization of Lactate Dehydrogenase on Tetraethylorthosilicate-Derived Sol-Gel Films for Application to Lactate Biosensor, Applied Biochemistry and Biotechnology 96 (2001) 303-310.

[5] A. Kumar, R. Malhotra, B.D. Malhotra, S.K. Grover, Co-immobilization of cholesterol oxidase and horseradish peroxidase in a sol-gel film. Analytica Chimica Acta 414 (2000) 43-50.

[6] B.C. Dave, J.M. Miller, B. Dunn, J.S. Valentine, J.I. Zink, Encapsulation of proteins in bulk and thin films sol gel matrices, Journal of sol gel science and technology 8 (1997) 629-634.

[7] S. Singh, R. Singhal, B.D. Malhotra, Immobilization of cholesterol esterase and cholesterol oxidase onto sol-gel films for application to cholesterol biosensor, Analytica Chimica Acta 582 (2007) 335-343.

[8] D.R. Azolin, C.C. Moro, T.M.H. Costa, E.V. Benvenutti, Effects of organic content and $\mathrm{H}_{2} \mathrm{O}$ /TEOS molar ratio on the porosity and pore size distribution of hybrid naphthaleneaminepropyl silica xerogel, Journal of Non-Crystalline Solids 337 (2004) 201-206.

[9] R.F.S. Lenza, W.L. Vasconcelos, Synthesis and properties of microporous sol gel silica membranes, Journal of Non-Crystalline Solids 273 (2000) 164169.

[10] Z.H. Zhou, J.M. Xue, J. Wanga, H.S.O. Chan, T. Yu, Z.X. Shen, $\mathrm{NiFe}_{2} \mathrm{O}_{4}$ nanoparticles formed in situ in silica matrix by mechanical activation, Journal of Applied Physics 91 (2002) 96015-6020. 
[11] R.F.S. Lenza, W.L. Vasconcelos, Preparation of Silica by Sol-Gel Method Using Formamide, Materials Research 4 (2001) 189-194.

[12] S. Duhana, N. Kishore, P. Aghamkar, S. Devi, Preparation and characterization of sol-gel derived silver-silica nanocomposite, Journal of Alloys and Compounds 507 (2010) 101-104. 